\title{
ATLASES OF FLOATING ICE
}

\author{
By Terence Armstrong \\ (Scott Polar Research Institute, Cambridge)
}

THERE is always a need for an up-to-date atlas which will show in some convenient manner the seasonal distribution of floating ice. The time was ripe for a new presentation of this information, and the U.S. Navy Hydrographic Office has very obligingly done the job by including a long section on ice in both the Arctic and Antarctic parts of its Oceanographic atlas of the polar seas. ${ }^{\mathrm{I}}$ This publication is primarily for scientific use. Geographical differences between Arctic and Antarctic, together with the wide difference in the amount known about the ice of each, has properly brought about differences in presentation. But the basic method is the same in each case. A series of monthly or half-monthly charts show average concentration and extreme limits of floating ice; and these are followed by another series showing actual concentration and limits at particular times and places. In addition, the Antarctic volume contains a generalized chart to show accessibility of coasts, and pays special attention to the northward drift of icebergs, while the Arctic volume includes a list of mean and extreme dates for freeze-up and break-up at $3^{8}$ selected coastal stations. Both have some explanatory text and a bibliography. Also worthy of mention in this journal, although not relevant to problems of floating ice, are sets of charts showing the probability of ship superstructure icing by seasons, based on wind and temperature records.

The kernel of this assembly of facts consists of the charts showing average concentration and extreme limits. The length of the period covered varies with availability of data: for the Antarctic, there are monthly charts during the summer and one composite chart for the seven winter months; for the Arctic, half-monthly charts during the summer and monthly during the winter. Each shows the area covered, on average for the period in question, by open water or by four different concentrations of ice (1/10-5/10, 5/10-8/10, 8/10-10/10, Io/10 consolidated). Maximum and minimum extent of any pack ice (I/10 or greater), and of pack ice beginning to cause difficulty to ships (5/10 or greater) is shown on the Arctic sheets, with a simpler version for the Antarctic. In addition, the volume of observations available in the Arctic is sufficient to permit qualification of each half-monthly chart with histograms showing further details of the ice at up to 49 selected points.

All this is excellent, and there is only one major criticism which must be made. When charts of this sort are compiled, full information about the ice of the whole region is never available. The plotting of an area of ice is likely to be done on the basis of actual observation of only a part or parts of that area. The rest is interpolation. This is likely to be the case with each observation of the series for which the mean is worked out. No indication as to how much interpolation there has been appears on the final chart, and so the user is unable to judge reliability from that aspect. Another factor which would help him to assess reliability is the number of observations on which the mean is based. There is awareness of this need, but the charts show only a very generalized reliability diagram. The fact is that the delineation of ice by isopleths, as used in these atlases (and in most others) is not compatible with the provision of detailed information on which to assess reliability. There are other methods, however, which are compatible. And here this reviewer must declare an interest, for he has recently published an ice atlas ${ }^{2}$ employing such a method, and other atlases on the same general lines will follow. ${ }^{3}$

It will be argued, of course, that the atlases under review do not require to show the ice situation to a greater degree of accuracy than is in fact shown, and that the simplicity of their method of presentation makes them better suited to certain uses. This may well be so, but in that case it must be recognized that some uses are better served by other methods; and 
therefore the limitations of this method should be explained in the text, for without knowledge of them some of the charts of mean ice conditions become positively misleading. The Antarctic charts for January and February, for instance, are dotted with small enclaves of one concentration of ice within a large area of another concentration. The exact location of these enclaves can have little significance, since the chart must be based on very scanty data. All that they should be taken to indicate is that the ice in that general area is often a mixture of the two sorts. But unwarned users may try to read more into them than that.

This was a disadvantage of the preceding ice atlas from this source. ${ }^{4}$ But although it has not been eradicated, there is undoubted improvement on the earlier work in other ways. For instance, the inclusion now of the charts of actual conditions in close propinquity to those showing means, does help to impress on users the wide range of variability from year to year, and the danger of thinking in terms of an "average" state of the ice. These two volumes give every appearance of having been compiled with care, and the end products are laid out both comprehensibly and pleasingly. The user who wishes, for instance, to correlate ice distribution with weather processes will find just the information he requires; while he who wishes to make, well in advance, the best possible estimate of his chances of sailing from, say, Pond Inlet to Resolute Bay on I August will be less well satisfied. But as the Preface states, "the atlas cannot possibly satisfy the needs of all users". Nevertheless, it will be, as it deserves, the standard work of reference for some time to come.

MS. received 7 November 1959

\section{REFERENCES}

1. Oceanographic atlas of the polar seas. Washington, D.C., Hydrographic Office, 1957-58. 2 vols. (H.O. Pub. No. 705.) [Part 1, Antarctic, 1957, \$2.50; Part 2, Arctic, 1958, \$5.00.]

2. Sea ice north of the U.S.S.R. London, Hydrographic Department, 1958. 2 vols. (H.D. 511 . $)\left[\begin{array}{lll}£ 5 & 12 & 0 .\end{array}\right]$

3. For instance, Ice atlas of Arctic Canada, by C. W. M. Swithinbank, to be published by the Defence Research Board of Canada.

4. Ice atlas of the northern hemisphere. Washington, D.C., Hydrographic Office, 1946. (H.O. [Pub.] No. 550.)

GEOGRAPHIG STUDY OF MOUNTAIN GLACIATION IN THE NORTHERN HEMISPHERE. W. O. Field and others. Parts I-IO. New York, American Geographical Society, r958, illus., maps.

THIs considerable work, undertaken on behalf of the U.S. Army Quartermaster Research and Engineering Command, is divided into ro Parts which are listed as follows:

Part I. Distribution, study, characteristics, classification and terminology of glaciers.

Part 2a. Glaciers of Alaska and adjoining parts of Canada.

Part 2b. ", , Western and Arctic Canada.

Part 3. " " the United States, Mexico, and the Northern Andes.

Part 4. " , " the North Atlantic Islands.

Part 5. $\quad, \quad$, Europe and Africa.

Part 6. , , ,Western Arctic and Eastern Asia.

Part $7 \mathrm{a}$ and $\mathrm{b}$. Glaciers of the Central Asian mountain system.

Part 8. Glacial geology; Cartography in the service of glaciology.

Part 9. Glaciers and human activities, avalanches, etc.

Part Io. Atlas of glaciers in the Northern Hemisphere.

The data have been compiled from observations made during the two years prior to I 957 by the Department of Exploration and Fieid Research of the American Geographical Society. 